\title{
Sustaining careers of physician-scientists in neonatology and pediatric critical care medicine: formulating supportive departmental policies
}

\author{
Helen Christou ${ }^{1,2,3}$, Maria L.V. Dizon ${ }^{4,5}$, Kathryn N. Farrow ${ }^{4,5}$, Sudarshan R. Jadcherla ${ }^{6,7}$, Kristen T. Leeman ${ }^{2,3}$, Akhil Maheshwari ${ }^{8}$, \\ Lewis P. Rubin', Brian K. Stansfield ${ }^{10,11}$ and David H. Rowitch ${ }^{12,13}$
}

\begin{abstract}
Understanding mechanisms of childhood disease and development of rational therapeutics are fundamental to progress in pediatric intensive care specialties. However, Division Chiefs and Department Chairs face unique challenges when building effective laboratory-based research programs in Neonatal and Pediatric Intensive Care, owing to high clinical demands necessary to maintain competence as well as financial pressures arising from fund flow models and the current extramural funding climate. Given these factors, the role of institutional support that could facilitate successful transition of promising junior faculty to independent research careers is ever more important. Would standardized guidelines of such support provide greater consistency among institutions? We addressed preliminary questions during a national focus group, a workshop and a survey of junior and senior academicians to solicit recommendations for optimal levels of protected time and resources when starting an independent laboratory. The consensus was that junior faculty should be assigned no more than 8 wk clinical service and should obtain start-up funds of $\$ 500 \mathrm{~K}-1 \mathrm{M}$ exclusive of a 5-y committed salary support. Senior respondents placed a higher premium on protected time than junior faculty.
\end{abstract}

$\mathrm{T}$ he care of critically ill pediatric patients has improved due to successful translation of basic discoveries into clinical practice. For example, clinical administration of exogenous surfactant has resulted from understanding the pathogenesis of respiratory distress syndrome (1). More recently, neurodevelopmental outcomes following hypoxic-ischemic encephalopathy have improved following rigorous preclinical study and clinical application of therapeutic hypothermia $(2,3)$. Continued progress is dependent upon new insights into disease and injury mechanisms, an enhanced understanding of genetic determinants of preterm birth, as well as the development of new animal models to facilitate preclinical avenues of research. To maintain innovation and a pipeline for novel therapies, the laboratory-based physician-scientist has an essential role in more rapidly translating advances in basic science to clinical application for critically ill patients.

Increasing challenges faced by academic physician-scientists have been recognized by the scientific community (4-6) and have prompted several initiatives and interventions aimed at retention of, and support for, physicians pursuing research careers. Successful examples include the Loan Repayment Program, the Early Stage and New Investigator designations by the National Institutes of Health (NIH), and the Pediatric Scientist Development Program (PSDP), which is supported by multiple organizations including the $\mathrm{NIH}$, the American Academy of Pediatrics, the March of Dimes, the Association of Medical School Pediatric Department Chairs, Paediatric Chairs of Canada, and Sick Kids Foundation. However, these efforts do not specifically address several challenges in the clinically intensive fields of Neonatal-Perinatal Medicine and Pediatric Critical Care Medicine where the competing demands for clinical mastery and academic productivity often conflict.

Based on recent surveys and input from junior faculty members in these clinical specialties (7), we observed significant variation among academic institutions in the amount and quality of support they provide. Additional guidelines might promote uniform levels of support and enhance career success of the clinician-scientist in Neonatal-Perinatal Medicine and Pediatric Critical Care Medicine. We have previously reported on institutional support recommendations for clinical and research protected time for NIH K-award holders (7). Here, we focus on what is needed to support career success at the critical transition between $\mathrm{K}$-award and R- or equivalent independent investigator funding for laboratory-based clinician-scientists in neonatology and pediatric intensive care specialties.

\footnotetext{
'Department of Pediatric Newborn Medicine, Brigham and Women's Hospital, Boston, Massachusetts; ${ }^{2}$ Department of Medicine and Division of Newborn Medicine, Boston Children's Hospital, Boston, Massachusetts; ${ }^{3}$ Harvard Medical School, Boston, Massachusetts; ${ }^{4}$ Department of Pediatrics Northwestern University Feinberg School of Medicine, Chicago, Illinois; ${ }^{5}$ Ann \& Robert H. Lurie Children's Hospital of Chicago, Chicago, Illinois; ${ }^{6}$ Nationwide Children's Hospital Research Institute, Columbus, Ohio; ${ }^{7}$ Ohio State University College of Medicine, Columbus, Ohio; ${ }^{8}$ Morsani College of Medicine, University of South Florida, Tampa, Florida; ${ }^{9}$ Department of Pediatrics, Paul L. Foster School of Medicine, Texas Tech University Health Sciences Center El Paso and El Paso Children's Hospital, El Paso, Texas; ${ }^{10}$ Department of Pediatrics, Augusta University, Augusta, Georgia; ${ }^{11}$ Vascular Biology Center, Augusta University, Augusta, Georgia; ${ }^{12}$ Division of Neonatology, University of California, San Francisco, California; ${ }^{13}$ Department of Paediatrics, University of Cambridge, Cambridge, UK. Correspondence: Helen Christou (hchristou@partners.org)

Received 10 May 2016; accepted 17 May 2016; advance online publication 24 August 2016. doi:10.1038/pr.2016.147
} 


\section{SUMMARY OF PAS WORKSHOP}

The primary goals and content of the PAS workshop were:

1. To provide an overview of opportunities for junior faculty in academic institutions including, (i) availability of T32 or other significant training mechanisms (e.g., PSDP, institutional K12), (ii) general trends in faculty recruitment including appointment rank and membership in graduate school programs, and (iii) start-up funds and accessible resources including sufficient laboratory space. Dr. Jeffrey Fineman, Chief of the Division of Pediatric Critical Care at the University of California San Francisco and Dr. Stella Kourembanas, Chief of the Division of Newborn Medicine at Boston Children's Hospital presented their perspectives.

2. To present objective criteria for evaluation of the long-term impact of training programs. Dr. Margaret K. Hostetter, Director of the PSDP, presented metrics and Dr. Tonse Raju, Branch Chief at the Eunice Kennedy National Institute of Child Health and Human Development (NICHD), presented the outcome data for the NICHD T32 mechanism.

3. To establish recommendations for support needed from clinical divisions and/or departments and help set a consistent national standard of expectations to enhance success of junior faculty physician-scientists and sustain academic productivity.

\section{SURVEY RESULTS}

We designed a 25-question survey and invited participation from all workshop participants and division chiefs in Neonatology and Pediatric Critical Care Medicine in the United States and Canada. We also asked division chiefs to share the survey with the faculty members of their divisions.

\section{Characteristics of Respondents (Education, Area of Interest, Academic Success)}

We received a total 71 responses (denominator unknown). The characteristics of the respondents are shown in Table 1. There were eight trainees (fellows) in the group, and we analyzed their responses separately. All respondents were affiliated with an academic institution, 52\% indicated they are on a tenure track and 39\% participate in a graduate program. All academic ranks were represented: $4.8 \%$ were Instructors, $38 \%$ Assistant Professors, 9.5\% Associate Professors, and 47.6\% were Professors. All but one of the respondents (98\%) were physicians (MD or DO) and $40 \%$ had an advanced degree (14.2\% had a PhD while $25.4 \%$ had a Masters degree). About $40 \%$ of respondents participated in a T32 program or in the PSDP. Half of the faculty had been or were currently mentored from within their division and half had primary research mentors who were in a different clinical division or field. About half of the respondents in our sample (49.2\%) performed their research in a basic science setting and $50.1 \%$ worked in a primarily pediatric or translational setting. A small percentage
Table 1. Respondent characteristics

\begin{tabular}{|c|c|}
\hline Respondent characteristics & Percentage \\
\hline Academic affiliation & 100 \\
\hline Tenure track & 52 \\
\hline Participation in graduate program & 39 \\
\hline \multicolumn{2}{|l|}{ Academic Rank: } \\
\hline Instructor & 4.8 \\
\hline Assistant Professor & 38.1 \\
\hline Associate Professor & 9.5 \\
\hline Professor & 47.6 \\
\hline \multicolumn{2}{|l|}{ Degree: } \\
\hline Medical (MD or DO) & 98 \\
\hline Doctorate (PhD) & 14.2 \\
\hline Masters & 25.4 \\
\hline Participation in T32 & 30.2 \\
\hline Participation in Pediatric Scientist Development Program & 9.5 \\
\hline \multicolumn{2}{|l|}{ Mentoring: } \\
\hline Primary mentor within the specialty & 50 \\
\hline Primary mentor outside the specialty & 50 \\
\hline \multicolumn{2}{|l|}{ Research Setting } \\
\hline Basic Science Laboratory & 49.2 \\
\hline Pediatric or Translational & 50.1 \\
\hline \multicolumn{2}{|l|}{ Publications: } \\
\hline In Basic Science Journals & 53.3 \\
\hline In Pediatric Journals & 35 \\
\hline In Translational Journals & 11.7 \\
\hline Metrics for Promotion: & 100 \\
\hline \multicolumn{2}{|l|}{ Publications, Funding, Combination } \\
\hline \multicolumn{2}{|l|}{ Funding: } \\
\hline NIH Career Development Award (K08, K23, K99) & 37.5 \\
\hline Other Career Development Award & 60.7 \\
\hline NIH R01 Award & 39 \\
\hline NIH R01 Award Renewal & 25 \\
\hline Multiple NIH R01 Awards & 12.7 \\
\hline
\end{tabular}

There were eight trainees (fellows) in the group and their responses were analyzed separately.

(6.5\%) of respondents reported they worked in both settings. The majority of respondents (53.3\%) reported that their mentors published primarily in basic biomedical science journals as opposed to primarily pediatric (35\%) or other professional journals (11.7\%). About one third of respondents (37.5\%) had been recipients of a career development award from the NIH (e.g., K08, K23, K99, or K12) while about two thirds (60.7\%) were supported by different extramural career development awards. Thirty-nine percent of respondents have been successful in obtaining a R01 grant from the NIH and 25\% of respondents have successfully renewed their R01 grants, while $12.7 \%$ have obtained more than one R01. All of the respondents indicated that the metrics for their academic advancement were 
publications and funding or a combination of factors including publications and grants. The majority of respondents (76\%) indicated that their understanding of the term "physician-scientist" is a practicing physician who has an active laboratory research program; $24 \%$ indicated this term can include nonpracticing physicians who have an active laboratory research program.

\section{Departmental Support}

About two thirds of respondents (62\%) felt that they were offered sufficient protected time by their departments to be able to carry out laboratory-based research. In order to understand perceptions about the ideal duration of clinical service

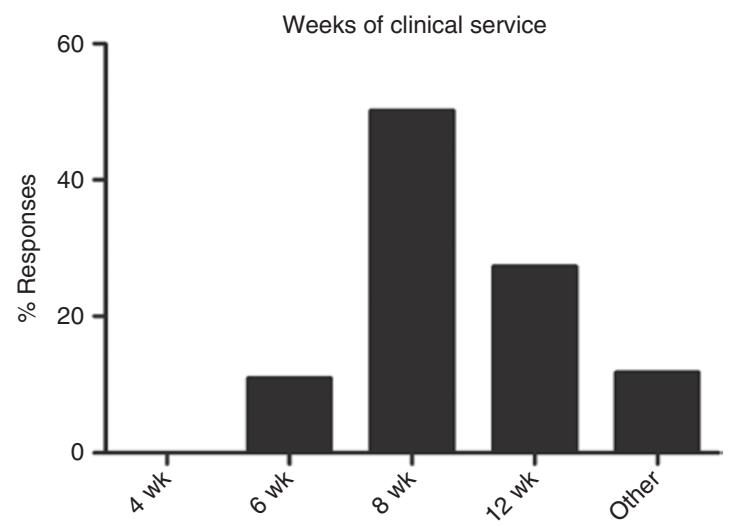

Figure 1. Distribution of responses regarding maximum number of weeks of clinical service time.
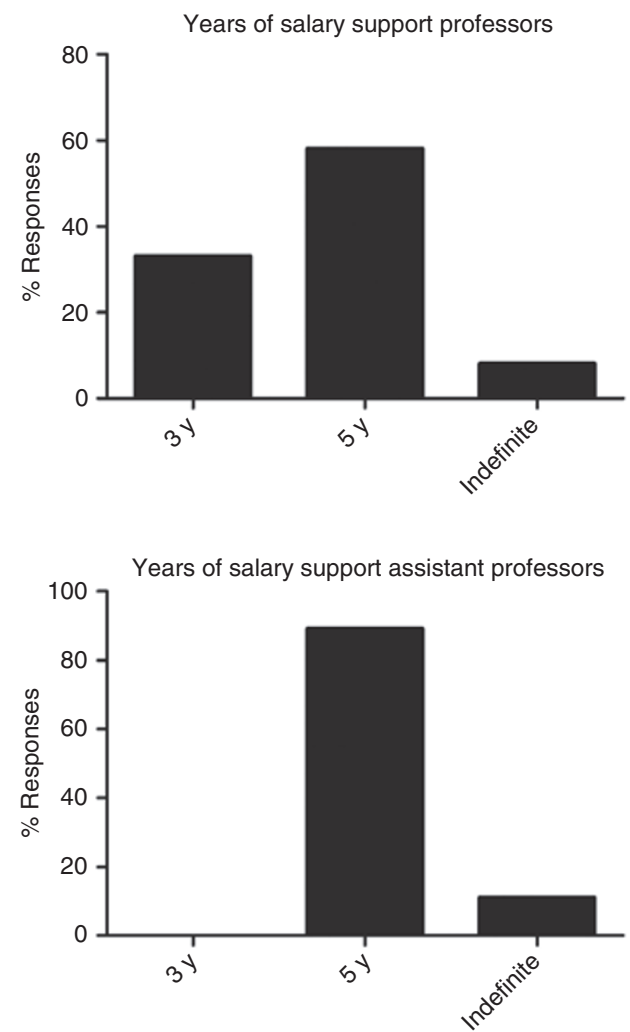

time per year, we asked, "What is the maximum clinical service time in order to remain competitive in starting one's own lab?" Over $60 \%$ of respondents suggested that restricting clinical service to no more than $8 \mathrm{wk}$ is necessary for successful primary investigation $(50.1 \%$ answered $8 \mathrm{wk}, 10.9 \% 6 \mathrm{wk}$, and $27.3 \% 12 \mathrm{wk}$ ) (Figure 1). Additional answers indicated a range from 9 to $20 \mathrm{wk}$; one respondent suggested duration of clinical time can vary based on individual circumstances. Trainees and junior faculty tended to undervalue protected research time, while more senior faculty identified shorter clinical requirements as necessary for junior investigator success. Regarding start-up resources, 62 percent of respondents felt their department provided them with an adequate start-up package. We then asked, "What is the ideal start-up package in terms of duration of salary support and dollars" allocated. Most respondents (69\%) indicated $5 \mathrm{y}$ as the ideal duration of initial salary support, while $21.8 \%$ felt that 3 y were sufficient. There seems to be consensus among faculty at all academic ranks (Figure 2). The average number of years for salary support perceived as ideal was 4.2 among Professors, 3.8 among Associate Professors, 5 among Assistant Professors, and 4.3 among Instructors. Trainee responses were similar, 4.5 being the average duration of salary support perceived as adequate. A small percentage of respondents suggested the duration of salary support should be indefinite. Regarding the dollar amount, $70 \%$ of respondents indicated that the ideal start-up amount should be $\$ 500 \mathrm{~K}-1 \mathrm{M}, 22 \% \%$ responded $\$ 1-1.5 \mathrm{M}$ and $8 \%$ responded $\$ 1.5-2 \mathrm{M}$. Only half of the trainees chose to answer this question, the most common response being
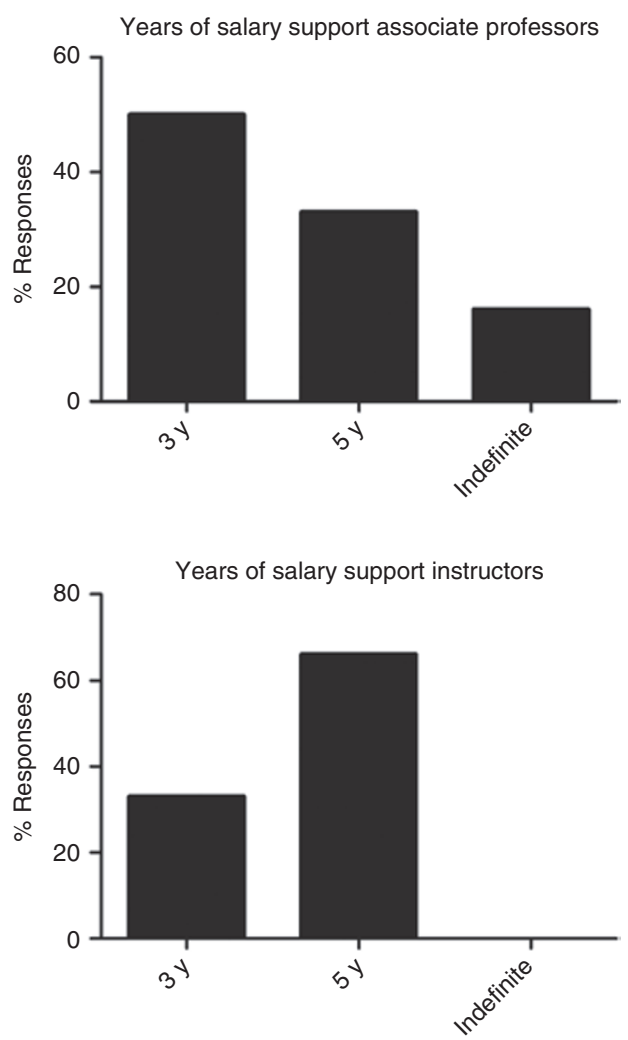

Figure 2. Distribution of responses regarding ideal duration of initial salary support by academic rank. 
\$1-1.5 M. Among Full Professors, the dollar amount perceived as ideal varied, $79 \%$ of respondents indicating $\$ 500 \mathrm{~K}-1 \mathrm{M}$, $12.5 \%$ indicating $\$ 1-1.5 \mathrm{M}$ and $8.5 \%$ indicating $\$ 1.5-2 \mathrm{M}$. In contrast, responses from Associate Professors were uniform; all considered $\$ 500 \mathrm{k}-1 \mathrm{M}$ as the ideal amount for start-up support. Interestingly, the highest percentage of responses from Assistant Professors was in the $1-1.5 \mathrm{M}$ and $1.5-2 \mathrm{M}$ categories with 40 and $10 \%$, respectively. This feedback is especially important since junior faculty are most acutely aware of recent trends toward higher packages in the basic sciences, as well as the needs to sustain laboratory programs over several years, despite the challenging NIH funding climate.

In summary, the data presented here (Table 2) support that senior faculty rank the importance of protected research time higher than the start-up funds amount, while junior faculty value a higher start-up monetary value more than protected time per se. There seems to be agreement between the two groups on the duration of salary support.

\section{Major Challenges for Lab-Based Physician-Scientists in} Neonatal-Perinatal Medicine and Pediatric Critical Care Medicine We received 50 responses to the open ended questions, "What are the Major Challenges faced by lab-based physicianscientists in NICU and PICU?" and "Are there other challenges that need to be addressed?" The following three themes emerged: (i) Funding: cited as major challenges were lower $\mathrm{NIH}$ pay lines, trainee debt, moonlighting incentives, lab personnel support, competition with full-time (nonclinical) researchers, and lack of ongoing support from large labs and/ or more senior investigators; (ii) Protected time: the most common responses were burdensome RVU requirements, time to comply with regulatory requirements for research, disruptive clinical scheduling including in-hospital call, increasing requirements for clinical practice such as electronic health

Table 2. Frequency of responses regarding institutional support for junior faculty by academic rank

\begin{tabular}{lcc}
\hline \multicolumn{2}{c}{$\begin{array}{c}\text { Senior faculty (Associate } \\
\text { and Full Professors) }\end{array}$} & $\begin{array}{c}\text { Junior faculty (Instructors } \\
\text { and Assistant Professors) }\end{array}$ \\
\hline Maximum weeks of clinical service \\
$4 \mathrm{wk}$ & $0 \%$ & $0 \%$ \\
$6 \mathrm{wk}$ & $3.5 \%$ & $21 \%$ \\
$8 \mathrm{wk}$ & $69 \%$ & $33 \%$ \\
$12 \mathrm{wk}$ & $24 \%$ & $37.5 \%$ \\
Other & $3.5 \%$ & $8.5 \%$ \\
Years of salary support & & \\
$3 \mathrm{y}$ & $37 \%$ & $5 \%$ \\
$5 \mathrm{y}$ & $53 \%$ & $86 \%$ \\
Indefinite & $10 \%$ & $9 \%$ \\
Amount of start up funds & & $52 \%$ \\
\$500k-1M & $84 \%$ & $39 \%$ \\
\$1-1.5M & $10 \%$ & $9 \%$ \\
\$1.5-2M & $6 \%$ & \\
\hline
\end{tabular}

record documentation, ICD10 coding, maintenance of certification, work-life balance, and need to maintain one's clinical skills; (iii) Mentoring: major challenges in this area were inadequate mentorship-training during fellowship and early career, lack of opportunities to network and receive mentoring/sponsorship from mentors outside one's department or institution, sometimes divergent expectations from clinical and research mentors, and limited number of role models.

The respondents made several suggestions to begin to address these challenges including the development of more opportunities for group science, opportunities for more flexible careers, better training, acknowledgement of generationspecific expectations for work-life balance, nontraditional departmental support for physician-scientists, efforts to enhance diversity, professional mentorship and mentoring networks, establishment of new metrics for academic productivity, and addressing unique challenges faced by smaller institutions having more limited resources.

\section{DISCUSSION}

Systemic challenges in the biomedical research enterprise have been identified and discussed extensively in the last 5 y. In 2014, Alberts et al. (8) encouraged discussion of these critical issues among academic institutions, scientific societies, and relevant constituencies. An adverse funding climate which results in hypercompetition for limited resources presents a challenge for all scientists (9-12). Nevertheless, some unique challenges are faced by physician-scientists and particularly physicianscientists in intensive care-based specialties such as neonatology and pediatric critical care (7) (Table 3). Our goal was to focus on these unique challenges and list common problems for laboratory-based pediatric intensivist-scientists through interinstitutional dialogue, collaboration, and establishment of national guidelines. National interventions currently being explored for physician-scientists might not address the unique challenges for pediatric intensivist-scientists at the academic institutional and hospital levels (13). The three themes that emerged from our workshop and follow-up survey relate to training and mentorship, clinical requirements, and departmental financial support.

\section{Training and Mentorship}

The importance of research training and mentorship during fellowship is widely recognized to be a critical component in career success. When used wisely, mandated procedures such as scholarship oversight and duty hour restriction policies can enhance the research experience during fellowship and contribute to productive mentoring relationships. But beyond the structured environment of a fellowship program, division, departmental, and institutional leaders should adopt policies that emphasize desirable additional training and provide oversight during the transitional vulnerable junior faculty period. For example, departmental leaders can ensure that primary mentors are not too junior in their own careers and have a proven track record of mentoring. Mentorship should expand beyond the boundaries of the home institution. 
Table 3. Challenges for research scientists

\begin{tabular}{lll}
\hline All scientists & Physician-scientists & $\begin{array}{l}\text { Neonatology and pediatric critical care } \\
\text { physician-scientists }\end{array}$ \\
\hline - Hypercompetitive environment & - Clinical productivity & $\bullet$ Need for clinical mastery \\
- Lack of funding & $\bullet$ Increasing number of unfunded compliance regulations & $\bullet$ In-house call \\
& & - Demanding clinical schedules \\
\hline
\end{tabular}

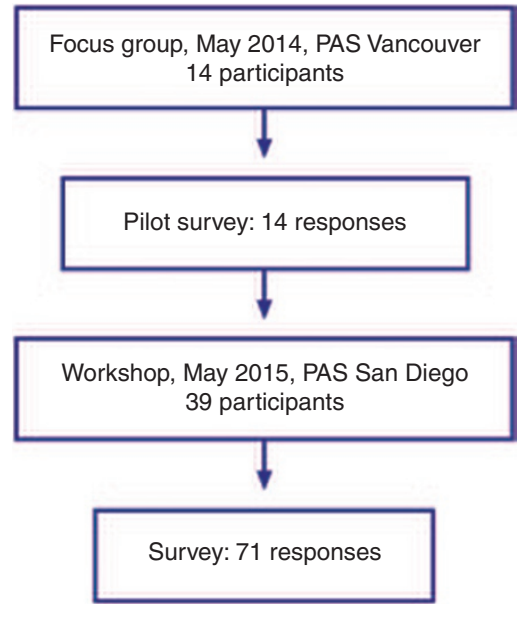

Figure 3. Study flow.

Creating opportunities for networking, interinstitutional collaborations, and mentoring are low-cost interventions that provide specific expertise and encourage mutually beneficial relationships. Professional societies are a critical part of the solution. Initiatives such as the Young Investigator Coaching Program of the Society for Pediatric Research and the Young Investigator Program of the Perinatal Research Society fill many of these needs and should be expanded. Mentorship should be diverse, multidisciplinary, and trans-generational $(14,15)$ with tools to track career development for physicianscientists. However, each institution must carefully monitor and mentor its own junior faculty as a matter of priority. An important component in this process is providing training for faculty mentors and this has been successfully instituted in some academic centers (16).

\section{Clinical Requirements}

The clinical requirements for faculty in Neonatology and Pediatric Critical Care may be more burdensome than for faculty of other pediatric subspecialties. The need for continued procedural proficiency in a high stress environment and mandated in-house overnight call are part of clinical practice in these specialties but can impede research productivity. Although wide variation exists in amount of clinical service time across institutions (7), our survey suggests a consensus among intensive care faculty that clinical service exceeding $8 \mathrm{wk}$ per year may hinder a productive research career, especially in the earliest career stage. Similarly, there are wide variations in the number of nights of call across academic institutions and "in house" residency requirements
(7). Some departmental leaders aim to distribute night call equally among faculty in order to enhance faculty cohesiveness, while others aim to distribute night call in proportion to daytime service so that clinical duties reflect faculty areas of focus. We recognize that institutional affiliations, training requirements, availability of physician extenders (nurse practitioners, physician assistants), and other factors contribute to these decisions. In conjunction with these needs, we propose departmental leaders construct individualized faculty clinical schedules informed by programmatic needs and departmental priorities that also are consistent with a faculty member's career stage and progress. For example, a national forum determined that 24 night calls per year should be the maximum for individuals with a NIH K-award (7). An area of concern for all physician-scientists is the increasing burden of compliance regulations. While departmental leaders can support efforts to reduce regulatory and compliance requirements for physician-scientists, they can also assist by allocating administrative support for faculty to meet these increased time demands. Finally, a burden for administrators results from "funds flow" systems of reimbursement for physician services. These models do not encompass resource for research per se and so it is up to Division Chiefs or Department Heads to repurpose these funds to support the research mission, which is a challenge for various reasons at some institutions.

\section{Departmental Support/Funding}

Allocation of funds for salary support and research expenses (the "start-up" package) is a standard process for newly hired faculty, but large disparities across institutions in both duration and resource support exist. Based on our survey among neonatologists and pediatric critical care specialists, $5 \mathrm{y}$ of salary support is considered adequate by most respondents but $3 \mathrm{y}$ of support is inadequate. Along with salary support, sufficient resources must be in place to initiate and sustain an extramurally-funded research career. Start-up packages vary widely with allocation of resources from $\$ 100,000$ to $>\$ 1 \mathrm{M}$ across institutions. While most respondents indicated that $\$ 500 \mathrm{k}-1 \mathrm{M}$ would be adequate, senior faculty more often favored smaller start-up packages compared to junior faculty; this might imply that senior faculty and leaders are "out of touch" with the current trends in the basic sciences in the United States. For example, resources of $>\$ 1 \mathrm{M}$ are associated with basic science start-up packages at many institutions. The responses of senior faculty may also be shaped by the fact that universities are now picking up a larger share of the total costs of research activities (4). Institutional factors such as availability of core facilities, technical assistants, 
research infrastructure, and grant review support can facilitate junior faculty success despite smaller start-up dollar amounts. In addition, institutional bridge-funding mechanisms become particularly important during periods of lapses in federal funding.

Although our survey results may be more representative of the academic faculty community in neonatology and pediatric critical care, several limitations and potential confounding factors may have introduced bias. Physician-scientists who are more invested in this topic are possibly over-represented among respondents, introducing potential selection bias. Our survey also did not address the contributions of respondents' age and gender in their opinions. We also had a bimodal skew with the larger number of respondents at the Assistant or Full Professor levels and fewer mid level faculty at the Associate Professor rank. It is possible that these two groups may be prone to bias stemming from being recent recipients of research support or as the departmental leaders who make these decisions, respectively. We did not collect information on the number of division chiefs or department chairs who participated in the survey. Finally, although it would have been useful to obtain the European and Australasian perspectives, our survey and results are limited toand make specific recommendations for-academic medical practice in the United States.

In summary, based on a national workshop and survey, we offer several concrete suggestions for departmental leaders to consider in supporting career development of physician-scientists in Neonatology and Pediatric Critical Care Medicine. Our recommendations are for $5 \mathrm{y}$ of salary support, no more than $8 \mathrm{wk}$ of service time, limited night call, high-quality laboratory space in a supportive scientific environment, and start up resources of $\$ 500-1 \mathrm{M}$. There is consensus that these interventions are essential for success in developing the careers of our most promising clinician scientists who will provide future insights into disease mechanism as well as novel diagnostic and therapeutic advances.

\section{METHODS}

We held a focus group discussion with junior faculty in NeonatalPerinatal Medicine and Pediatric Critical Care Medicine at the 2014 Pediatric Academic Societies national meeting. This discussion elicited what junior faculty felt were the significant barriers to their career success. In response to the focus group discussion, we administered a pilot survey and organized a workshop during the 2015 Pediatric Academic Societies Annual Meeting at which academic leaders, administrators, and junior faculty members reviewed these issues with the goal of generating strategies to enhance research productivity and career success. Then, we designed a comprehensive 25-question survey and invited national participation from all workshop participants, pediatric department chairs, and division chiefs in Neonatology and Pediatric Critical Care Medicine (Figure 3).

\section{ACKNOWLEDGMENTS}

We acknowledge the support of the Pediatric Academic Societies that sponsored our workshop at the 2015 national meeting, our invited guests for their thoughtful input, and all the participants of the focus group, workshop, and electronic survey. We are grateful to Mary Ulman for administrative assistance.

Disclosure: No financial assistance was received in support of this work. There are no financial ties to products or conflicts of interests in this study.

\section{REFERENCES}

1. Avery ME, Mead J. Surface properties in relation to atelectasis and hyaline membrane disease. AMA J Dis Child 1959;97(5, Part 1):517-23.

2. Gluckman PD, Wyatt JS, Azzopardi D, et al. Selective head cooling with mild systemic hypothermia after neonatal encephalopathy: multicentre randomised trial. Lancet 2005;365:663-70.

3. Shankaran S, Laptook AR, Ehrenkranz RA, et al.; National Institute of Child Health and Human Development Neonatal Research Network. Whole-body hypothermia for neonates with hypoxic-ischemic encephalopathy. N Engl J Med 2005;353:1574-84.

4. Daniels, R.J. A generation at risk: young investigators and the future of the biomedical workforce. Proc Natl Acad Sci USA 2015; 112; 313-8.

5. Garrison HH, Deschamps AM. NIH research funding and early career physician scientists: continuing challenges in the $21^{\text {st }}$ century. FASEB J 2014;28:1049-58.

6. Morel PA, Ross G. The physician scientist: balancing clinical and research duties. Nat Immunol 2014;15:1092-4.

7. Oishi PE, Klein OD, Keller RL; University of California San Francisco Neonatology and Pediatric Critical Care Early Faculty Development Committee. Developing physician-scientists in the fields of neonatology and pediatric critical care medicine: an effort to formulate a departmental policy. J Pediatr 2013;163:616-7.e1.

8. Alberts B, Kirschner MW, Tilghman S, Varmus H. Rescuing US biomedical research from its systemic flaws. Proc Natl Acad Sci USA 2014;111: 5773-7.

9. Alberts B, Kirschner MW, Tilghman S, Varmus H. Opinion: Addressing systemic problems in the biomedical research enterprise. Proc Natl Acad Sci USA 2015;112:1912-3.

10. Hobin JA, Deschamps AM, Bockman R, et al. Engaging basic scientists in translational research: identifying opportunities, overcoming obstacles. J Transl Med 2012;10:72.

11. Nathan DG, Wilson JD. Clinical research and the NIH-a report card. N Engl J Med 2003;349:1860-5.

12. Zemlo TR, Garrison HH, Partridge NC, Ley TJ. The physician-scientist: career issues and challenges at the year 2000. FASEB J 2000;14:221-30.

13. Nichols DG, Lister G. The physician-scientist workforce and board certification. JAMA Pediatr 2015;169:417-8.

14. Cornfield DN, Lane R, Rosenblum ND, et al. Patching the pipeline: creation and retention of the next generation of physician-scientists for child health research. J Pediatr 2014;165:882-4.e1.

15. Milewicz DM, Lorenz RG, Dermody TS, Brass LF; National Association of MD-PhD Programs Executive Committee. Rescuing the physician-scientist workforce: the time for action is now. J Clin Invest 2015;125:3742-7.

16. Tsen LC, Borus JF, Nadelson CC, Seely EW, Haas A, Fuhlbrigge AL. The development, implementation, and assessment of an innovative faculty mentoring leadership program. Acad Med 2012;87:1757-61. 